\title{
Tuning ordered pattern of Pd species through controlled block copolymer self- assembly
}

Article

Accepted Version

De Rosa, C., Auriemma, F., Malafronte, A., Di Girolamo, R., Lazzari, M., Nieto-Suarez, M., Hermida-Merino, D., Hamley, I. W. and Portale, G. (2016) Tuning ordered pattern of Pd species through controlled block copolymer self-assembly. Journal of Physical Chemistry B, 120 (27). pp. 6829-6841. ISSN 1520-5207 doi: https://doi.org/10.1021/acs.jpcb.6b04380 Available at https://centaur.reading.ac.uk/66600/

It is advisable to refer to the publisher's version if you intend to cite from the work. See Guidance on citing.

To link to this article DOI: http://dx.doi.org/10.1021/acs.jpcb.6b04380

Publisher: American Chemical Society

All outputs in CentAUR are protected by Intellectual Property Rights law, including copyright law. Copyright and IPR is retained by the creators or other copyright holders. Terms and conditions for use of this material are defined in the End User Agreement. 


\section{CentAUR}

Central Archive at the University of Reading

Reading's research outputs online 


\section{Tuning Ordered Pattern of Pd Species Through}

\section{Controlled Block Copolymer Self-assembly}

Claudio De Rosa,${ }^{1}$ Finizia Auriemma, ${ }^{1}$ Anna Malafronte,,${ }^{1, *}$ Rocco Di Girolamo, ${ }^{1}$ Massimo

Lazzari, ${ }^{2}$ Marina Nieto Suárez, ${ }^{2}$ Daniel Hermida-Merino, ${ }^{3}$ Ian William Hamley, ${ }^{4}$ Giuseppe

\section{Portale $^{5}$}

${ }^{1}$ Dipartimento di Scienze Chimiche, Università di Napoli Federico II, Complesso Monte S. Angelo, Via Cintia, 80126, Napoli, Italy. ${ }^{2}$ Centro Singular de Investigación en Química Biolóxica e Materiais Moleculares (CiQUS), Universidade de Santiago de Compostela, Campus Vida, C/ Jenaro de la Fuente, 15782, Santiago de Compostela, Spain. ${ }^{3}$ European Synchrotron Radiation Facility (ESRF), 6 rue Jules Horowitz, BP 220, 38043, Grenoble, Cedex 9, France.

${ }^{4}$ School of Chemistry, Pharmacy and Food Biosciences, University of Reading, Whiteknights, Reading RG6 6AD, UK. ${ }^{5}$ Macromolecular Chemistry \& New Polymeric Materials, Zernike Institute for Advanced Materials, Nijenborgh 4, 9747 AG Groningen, The Netherlands.

\footnotetext{
* To whom correspondence should be addressed. Telephone: ++39 081 674309; Fax ++39081 674090; e-mail: anna.malafronte@unina.it.
} 
ABSTRACT We report a systematic investigation of nanocomposites based on polystyreneblock-poly(ethylene oxide) copolymers (PS-b-PEO), characterized by selective inclusion of palladium (Pd) species in the PEO domains. PS- $b$-PEO samples of different total molecular mass self-assemble in a cylindrical microphase-separated morphology, where vertically aligned PEO cylinders with different diameters depending on the molecular mass, are organized in a hexagonal array of different lateral spacing. The cylindrical nanostructure is maintained after the selective inclusion of Pd species (Pd-acetate and Pd nanoparticles after reduction of Pd ions of the salt) in the PEO cylinders, so that the characteristic sizes (diameter and lateral spacing) of the included Pd species are tuned by the characteristic sizes of the block copolymer template, which are regulated by the molecular mass. The treatment of the nanocomposites at elevated temperatures in air removes the polymer matrix and leads to the formation of arrays of $\mathrm{PdO}$ nanoparticles covering a solid support. The pattern of $\mathrm{PdO}$ nanoparticles is characterized by different particles diameters and gap distances, mirroring the pattern and the characteristic nanodimensions of the parent block copolymers used as template.

\section{INTRODUCTION}

Noble-metal nanoparticles ( $\mathrm{Au}, \mathrm{Ag}, \mathrm{Pt}, \mathrm{Pd})$ are of substantial interest for various scientific and technical applications. ${ }^{1-5}$ Due to the small size effect and extremely large specific surface area, they exhibit a number of unique optical, electronic and catalytic characteristics compared to bulk materials. In particular, palladium (Pd) and palladium oxide (PdO) nanoparticles (NPs) synthesis has gained considerable interest in the last few decades due to their numerous potential utilizations. ${ }^{3,6-11}$ Pd NPs, in particular, show high activity and selectivity in numerous catalytic processes. ${ }^{6-8} \mathrm{Pd}$ is the metal used for the catalytic formation of C-C bonds, one of the most useful transformations in organic synthesis. Concerning PdO, it has been typically used as catalysts in 
catalytic combustion of natural gas (methane) ${ }^{9,10}$ or liquid-phase oxidation of alcohols with oxygen. ${ }^{11}$ For these reasons, since the seventies, a huge variety of homogeneous catalytic systems based on $\mathrm{Pd}(\mathrm{II})$ or $\mathrm{Pd}(0)$ have been studied and have become a strategic tool for organic transformation and total synthesis. Because sustainable development involves the utilization of reusable catalysts, the search for new catalytic systems to replace existing homogeneous ones is one important issue. ${ }^{8,12}$ In this context, the immobilization of nanoparticles on a solid support is an interesting alternative since the catalyst can be recycled by simple filtration. Furthermore, immobilizing nanoparticles onto solid supports can minimize atom-ion leaching from the particles. ${ }^{8,} 12$ Palladium has the potential to play a major role in virtually every aspect of the envisioned hydrogen economy, including hydrogen purification, storage, detection, and fuel cells. ${ }^{13-14}$ Palladium is also used as a precoating materials for electroless deposition of copper used for micro contacts, and many electronic devices, such as resistors, use compositions containing palladium.

For all these applications, distribution of nanoparticles in a patterned form may be more suitable and, since the majority of unique nanoparticles properties are highly microstructuredependent, forming Pd and PdO arrays on solid supports with a precise control of nanoparticles dimensions and spacing is an important issue.

In order to fabricate an ordered array of nanoparticles, it is possible to deposit nanoparticles onto a solid substrate from a solution of nanoparticles. However, a perfect array of nanoparticles is rarely achieved, particularly over an extended area, because of uncontrolled formation of defects in the self-assembling process of the nanoparticles induced by the solvent evaporation. ${ }^{15}$, 16 Alternatively, effective fabrication of a two-dimensional array of nanoparticles on solid 
substrates has been demonstrated by the utilization of block copolymers in a self-assembled arrangement. $^{17,19}$

A di-block copolymer molecule consists of two polymer chains attached with one end. It can self-assemble to form a nanoscale structure with a domain spacing that depends on molecular weight, segment size, and the strength of interaction between the blocks. ${ }^{20-22}$ A typical periodicity is in the range of 10-200 $\mathrm{nm}$. In linear AB diblock copolymers, the following four equilibrium morphologies have been identified in numerous systems: lamellar, hexagonally packed cylindrical, bicontinuous gyroid, and body-centered cubic, close-packed spherical. ${ }^{20-22}$ The use of block copolymers trapping nanoparticles has been proposed as a tool to prevent particles aggregation and produce uniform size nanoparticles. ${ }^{17-19}$ Advantages arise from the possibility of inducing long range order in the block copolymers nanostructures and, correspondingly, in the positioning of nanoparticles. Long-range alignment of nanostructures in block copolymer films can be obtained through the control of solvent evaporation, using electric fields or chemical or mechanical patterning. ${ }^{23}$ Nanodomains of self-assembled BCPs may act as hosts for sequestering nanofillers producing ordered nanocomposites with different morphologies, ${ }^{17-19}$ the size and shape of which may be conveniently tuned by changing the molecular weights and compositions of the $\mathrm{BCPs}{ }^{24}$ The key for the engineering of these materials is the ability to control the final morphology of $\mathrm{BCP}$ nanostructures and to achieve a selective infiltration of nanoparticles in the target nanodomains.

Here, we report a simple method to fabricate arrays of palladium (Pd) species and palladium oxide (PdO) nanoparticles with tunable dimensions and lateral spacing by using polystyreneblock-poly(ethylene oxide) copolymers (PS-b-PEO) as both stabilizers for nanoparticles and templates for controlling their distribution. The volume fraction of PEO blocks in the copolymers 
has been selected in order to obtain a cylindrical microphase-separated morphology, in which the PEO blocks form a hexagonal array of cylinders in the PS matrix. Thin films characterized by a high degree of perpendicular orientation of PEO cylinders over large areas have been obtained. The cylindrical self-assembled nanostructure formed from PS- $b$-PEO block copolymers has been used as host for selectively sequestering a nanoparticles precursor (palladium(II) acetate) in PEO domains. Then, two different methods have been used to obtain Pd NPs from the precursor in presence of the BCPs: electron irradiation of the thin films containing the BCPs and palladium precursor, and reduction in solution by thermal treatment before the preparation of the thin films. In both cases, highly ordered nanocomposite thin films based on PS-b-PEO matrices and Pd nanoparticles have been obtained. Furthermore, PdO nanoparticles of improved stability against aggregation have been obtained onto a solid and conductive support (silicon wafer) by treating the Pd containing BCP films in air at elevated temperatures. We were able to modulate the dimensions of Pd nanoclusters and PdO NPs and their inter-distance by using as template two PS- $b$-PEO copolymers having different molecular weights of both PS and PEO blocks.

\section{EXPERIMENTAL SECTION}

Materials. Two PS- $b$-PEO copolymers with different molecular mass of both PS and PEO blocks have been purchased from Polymer Source, Inc. and used without further purification. The number-average molecular mass of the BCPs are $43.0 \mathrm{Kg} \mathrm{mol}^{-1}\left(M_{n}^{\mathrm{PS}}=32.0 \mathrm{Kg} \mathrm{mol}^{-1}\right.$;

$M_{n}^{\mathrm{PEO}}=11.0 \mathrm{Kg} \mathrm{mol}^{-1}$, polydispersity 1.06$)$ and $136.0 \mathrm{Kg} \mathrm{mol}^{-1}\left(M_{n}^{\mathrm{PS}}=102.0 \mathrm{Kg} \mathrm{mol}^{-1} ; M_{n}^{\mathrm{PEO}}\right.$ $=34.0 \mathrm{Kg} \mathrm{mol}^{-1}$, polydispersity 1.18). The first PS- $b$-PEO sample with lower molecular mass will be denoted as SEO; the second, with higher molecular mass, will be named HSEO (Table 1). Palladium(II) acetate $\left(\mathrm{Pd}(\mathrm{Ac})_{2}\right)(98 \%)$ and toluene have been purchased from Sigma-Aldrich. 
Table 1. Average molecular mass $\left(M_{n}\right)$, polydispersity (PDI $\left.=M_{w} / M_{n}\right)$, volume fraction of the PEO block $\left(f_{P E O}\right)$, melting $\left(T_{m}{ }^{I}, T_{m}{ }^{I I}\right)$ and crystallization $\left(T_{c}\right)$ temperatures of the PEO blocks of the two samples of PS- $b$-PEO.

\begin{tabular}{|c|c|c|c|c|c|c|}
\hline Sample & $M_{n} \times 10^{3}{ }^{(\mathrm{a})}(\mathrm{g} / \mathrm{mol})$ & $M_{w} / M_{n}{ }^{(\mathrm{a})}$ & $f_{\mathrm{PEO}}(\%)^{(\mathrm{b})}$ & $T_{\mathrm{m}}{ }^{1}\left({ }^{\circ} \mathrm{C}\right)^{(\mathrm{c})}$ & $T_{\mathrm{m}}{ }^{\mathrm{II}}\left({ }^{\circ} \mathrm{C}\right)^{(\mathrm{c})}$ & $T_{\mathrm{c}}\left({ }^{\circ} \mathrm{C}\right)^{(\mathrm{c})}$ \\
\hline PS- $b$-PEO (SEO) & $32-b-11$ & 1.06 & 23 & 57 & 51 & -26 \\
\hline PS- $b$-PEO (HSEO) & $102-b-34$ & 1.18 & 23 & 61 & 65 & -25 \\
\hline
\end{tabular}

(a) Obtained by size exclusion chromatography (SEC) analysis. (b) Calculated from the values of density of PEO and PS of 1.064 $\mathrm{g} / \mathrm{cm}^{3}$ and $0.969 \mathrm{~g} / \mathrm{cm}^{3}$, respectively. ${ }^{33,34}$ (c) Determined by DSC analysis at scanning rate of $10{ }^{\circ} \mathrm{C} / \mathrm{min} . T_{m}{ }^{I}$ and $T_{m}{ }^{I I}$ are the melting temperatures measured in the first and second heating scans (Figure S1). 
Characterization of block copolymers. Differential scanning calorimetry (DSC) experiments have been carried out using a calorimeter Mettler Toledo (DSC-822), calibrated with indium, in a flowing $\mathrm{N}_{2}$ atmosphere. A scanning rate of $10{ }^{\circ} \mathrm{C} / \mathrm{min}$ has been used to record the first heating, cooling and second heating scans. Small- and wide-angle X-ray scattering (SAXS and WAXS) experiments have been performed at BM26B ${ }^{25}$ (DUBBLE) station of the European synchrotron radiation facility (ESRF), Grenoble, France, with X-ray wavelength of $1.033 \AA$. The beamline is particularly suited for SAXS/WAXS experiments on polymers. ${ }^{26}$ A modified DSC Linkam hot stage that allows the transmission of X-rays through mica windows has been employed. The samples have been heated from -50 to $150{ }^{\circ} \mathrm{C}$, then cooled from 150 to $-50{ }^{\circ} \mathrm{C}$ and finally heated again to $150{ }^{\circ} \mathrm{C}$. 240 frames have been collected during heating at $5{ }^{\circ} \mathrm{C} / \mathrm{min}$ (time step/frame equal to $30 \mathrm{~s}$, corresponding to a change of $2.5^{\circ} \mathrm{C}$ per step). The scattering from the empty sample holder has been subtracted. The thermogravimetric analysis (TGA) has been performed using a TGA Q5000 IR of TA Instruments, in a $100 \mathrm{ml} \mathrm{min}^{-1} \mathrm{~N}_{2}$ flow atmosphere and $10^{\circ} \mathrm{C} \mathrm{min}^{-}$ ${ }^{1}$ heating rate.

Preparation of the nanomaterials. Toluene solutions of HSEO and SEO of $1.5 \%(\mathrm{w} / \mathrm{w})$ concentration have been prepared. $\mathrm{Pd}(\mathrm{Ac})_{2}$ has been added into $\mathrm{BCP}$ solutions to obtain a concentration of $\approx 26$ and $53 \mathrm{wt} \%$ with respect to the $\mathrm{BCP}$, corresponding to mole ratio $\mathrm{Pd} / \mathrm{PEO}$ monomeric units equal to 0.20 and 0.40 , respectively. The $\mathrm{Pd}(\mathrm{II})$ reduction has been performed by heating the $\mathrm{BCP}-\mathrm{Pd}(\mathrm{Ac})_{2}$ solutions at $75^{\circ} \mathrm{C}$ or $85^{\circ} \mathrm{C}$ under vigorous, continuous stirring until the color of the solution becomes dark gray. Thin films have been prepared by spin coating (4000 rpm for $30 \mathrm{~s}$ ) solutions of neat $\mathrm{BCP}$, solutions of $\mathrm{BCP}$ and $\mathrm{Pd}(\mathrm{Ac})_{2}$ immediately after preparation ( $\mathrm{BCP}-\mathrm{Pd}(\mathrm{Ac})_{2}$ film) and solution of $\mathrm{BCP}$ and $\mathrm{Pd}(\mathrm{Ac})_{2}$ after thermal reduction of Pd(II) (BCP-PdT film). The oxidative treatments to remove the block copolymer matrix and 
produce the PdO NPs have been performed by heating the BCP thin films containing Pd species in air at $600^{\circ} \mathrm{C}$ for 4 hours.

Thin films characterization. Transmission electron microscopy (TEM) images have been obtained in bright field mode using a Philips EM 208S TEM with an accelerating voltage of 100 $\mathrm{kV}$. Thin films have been prepared by spin coating the toluene solutions on carbon coated copper grids. Field emission scanning electron microscopy (FESEM) images have been collected using Zeiss Ultra Plus field emission SEM (Centro de Apoyo Científico-Tecnológico, Universidade de Santiago de Compostela), equipped with an Inlens detector and a SE Everhart-Thornley Secondary Electron Detector, using accelerating voltages of 1.0 or $1.5 \mathrm{kV}$. The samples for FESEM observation have been prepared on silicon supports. TEM and FESEM analyses have been repeated on different regions of the specimens, in order to check that the morphology was uniform over the macroscopic area of the support. The results have been also confirmed by repeating the measurements on independent samples. The size and the center-to-center distances of PEO cylinders and of PdO nanoparticles have been calculated from the corresponding FESEM images using the ImageJ software (National Institutes of Health, available free of charge at WEB site rsb.info.nih.gov/ij/). At least 200 independent measurements have been taken in different locations of the FESEM image of the samples. The measurements have been also confirmed by repeating the analysis on the FESEM images of independent samples.

Grazing incident wide and small angle X-ray scattering (GIWAXS and GISAXS) experiments have been performed at station BM26B ${ }^{25,26}$ (DUBBLE) of the European synchrotron radiation facility (ESRF), Grenoble, France. The samples have been prepared on rectangular (5 x $10 \mathrm{~mm})$ silicon substrates. For GIWAXS experiments, the employed wavelength and sample-detector distance have been $1.033 \AA$ and $109.86 \mathrm{~mm}$, respectively. The X-ray incident angle has been set 
to $0.15^{\circ}$ and $0.12^{\circ}$ in the case of the BCP nanocomposites containing NPs of Pd species and support covered by PdO nanoclusters, respectively. For GISAXS experiments, two sample to detector distances ( $5 \mathrm{~m}$ and $2 \mathrm{~m}$ ) have been used to acquire data over a large angular range. The X-ray wavelength of $0.1 \mathrm{~nm}$ has been used. GISAXS images have been recorded using a high sensitive solid state silicon Pilatus P1M detector, with pixel size 172 x 172 microns. The angular scale and thus the module of the scattering vector $q$ scale (with $q=4 \pi \sin \theta / \lambda$ ) have been calibrated using the diffraction rings from standard silver behenate and rat tail collagen samples. Images have been recorded at an incident angle of $0.46^{\circ}\left(\alpha_{i}>\alpha_{c}\right)$, in order to separate the reflected and the refracted signals. In this approximation, the deviations from the distorted wave Born approximation (DWBA) with respect to the classical Born approxiamtion (BA) are minimized. Transverse $q_{y}$ cuts have been calculated at the Yoneda maximum using a Matlab code and provide in-plane scattering intensity. Best fits for the Pd containing copolymer and for the PdO sample have been obtained using a unified model introduced originally by Beaucage. ${ }^{27}$, ${ }^{28}$ The possibility to use the unified model for fitting GISAXS data has been discussed in details in the literature ${ }^{29,30}$ and it has been showed that the model gives realistic results when $\alpha_{i}>\alpha_{c}$ and the particle diameter is below $15 \mathrm{~nm}$. The thickness of films has been measured with an Alpha-Step IQ Surface Profiler (KLA TENCOR) by performing at least 5 independent measurements in different regions of the same sample and over different samples. The relative error is less than $10 \%$.

UV-Vis spectroscopy. UV-Vis spectra of the solution containing the BCP and palladium precursor before and after different heating times have been recorded with a JASCO $550 \mathrm{UV}$-Vis spectrophotometer. The cell with $1.0 \mathrm{~cm}$ path length has been used to record UV-Vis spectra between 330 and $700 \mathrm{~nm}$. The scan of toluene has been subtracted from the scan of the sample. 
Spectra have been recorded by adding $2 \mathrm{~mL}$ toluene to $1 \mathrm{~mL}$ of the initial solution containing 1.5 $\mathrm{w} / \mathrm{w} \mathrm{BCP}$ and $26 \mathrm{wt} \% \mathrm{Pd}(\mathrm{Ac})_{2}$ with respect to the $\mathrm{BCP}$.

Suzuki cross-coupling reaction. The thin films of BCP containing Pd species (prepared on glass substrates) have been placed into a glass flask. A solution of potassium carbonate (414 mg) in water $(2 \mathrm{~mL})$ has been added to a solution of phenylboronic acid (133 $\mathrm{mg})$ and 4-bromanisole $(100 \mu \mathrm{L})$ in absolute ethanol $(2 \mathrm{~mL})$. The so obtained mixture (total volume $4 \mathrm{~mL}$ ) has been added to the glass flask containing the thin films. The system has been heated to reflux by setting the hotplate temperature to $120{ }^{\circ} \mathrm{C}$. After $1 \mathrm{~h}$, the product has been extracted with dichloromethane (3 x $10 \mathrm{~mL})$, dried with anhydrous sodium sulfate and concentrated under

vacuum. The obtained solid product has been dissolved in chloroform and analyzed by ${ }^{1} \mathrm{H}$ NMR using $\mathrm{CHCl}_{3}(\delta=7.26 \mathrm{ppm}$ respect to TMS) as internal standard. Test experiments using films of neat BCP have been also performed as control experiments (vide infra) in Suzuki reaction.

\section{RESULTS AND DISCUSSION}

Characterization of block copolymers. We have used two samples of PS- $b$-PEO block copolymers, SEO and HSEO, with almost the same composition but different molecular mass of both PS and PEO blocks (Table 1).

Samples with volume fraction of PEO blocks around $20 \%$ have been purposely selected in order to obtain a cylindrical phase-separated morphology. The PEO block is crystalline with melting and crystallization temperature of $50-65^{\circ} \mathrm{C}$ and $-25^{\circ} \mathrm{C}$, respectively (Table 1 , see also Figure S1 of supporting information). According to literature, the crystallization temperature of PEO in PS- $b$-PEO copolymers is lower than that observed in PEO homopolymer $\left(40{ }^{\circ} \mathrm{C}\right) .{ }^{31,32}$

Wide angle X-ray scattering (WAXS) profiles of the as received SEO and HSEO block copolymers collected during the first heating scan are reported in Figure 1A and B, respectively. 
The WAXS profiles at room temperature (curves a of Figure 1A and B) show two distinct peaks centred at $d=4.6$ and $3.7 \AA\left(2 \theta(\lambda=1.033 \AA) \approx 13\right.$ and $\left.16^{\circ}\right)$, corresponding to the 120 and 032 planes of the monoclinic form of polyethylene oxide (PEO), ${ }^{35}$ superposed to an amorphous halo due to the contribution of amorphous phases of PEO and PS blocks. Increasing the temperature, the intensity of Bragg peaks decreases, due to gradual melting of PEO crystals, up to disappear at $\approx 60{ }^{\circ} \mathrm{C}$, indicating the complete PEO melting, in agreement with DSC data (curve a and d of Figure S1).

Small angle X-ray scattering (SAXS) profiles of the as received SEO and HSEO samples, collected simultaneously to the WAXS data, are reported in Figures 1A', A" and 1B', B', respectively. In the SAXS profiles recorded at lower temperatures (curves a-c of Figure 1A' and B'), the presence of Bragg reflections at values of the scattering vector $q=4 \pi \sin \theta / \lambda$ corresponding to ratios $q / q_{1}=1,4^{1 / 2}$ and $12^{1 / 2}$ in the case of SEO (Figure $1 \mathrm{~A}^{\prime}$ ) and $q / q_{1}=1$ and $7^{1 / 2}$ in the case of HSEO (Figure 1 B') suggests a pseudo-hexagonal arrangements of PEO cylinders in the PS matrix, in agreement with predictions valid in the strong segregation limit for BCPs with PEO volume fraction of $20 \%{ }^{36}$ The SAXS peak positions and the corresponding domains spacings are reported in Table S1. From the $d$-spacings values of the first peak $q_{1}$ it is possible to determine the center-to-center distance between the PEO cylinders $\left(d_{1} / \cos 30^{\circ}\right)$, that results of $\approx 35 \mathrm{~nm}$ in the case of SEO copolymer and $\approx 60 \mathrm{~nm}$ in the case of HSEO sample in the hypothesis of hexagonal morphology. As expected, a higher value is obtained in the case of the HSEO sample, according to the higher copolymer molecular mass.

The peaks of the hexagonal morphology are also visible after the PEO melting at temperatures higher than $60^{\circ} \mathrm{C}$ (curves $\mathrm{f}$ and $\mathrm{g}$ of Figure 1A' and curves d-f of Figure 1B') indicating a phase separated morphology also in the melt. 

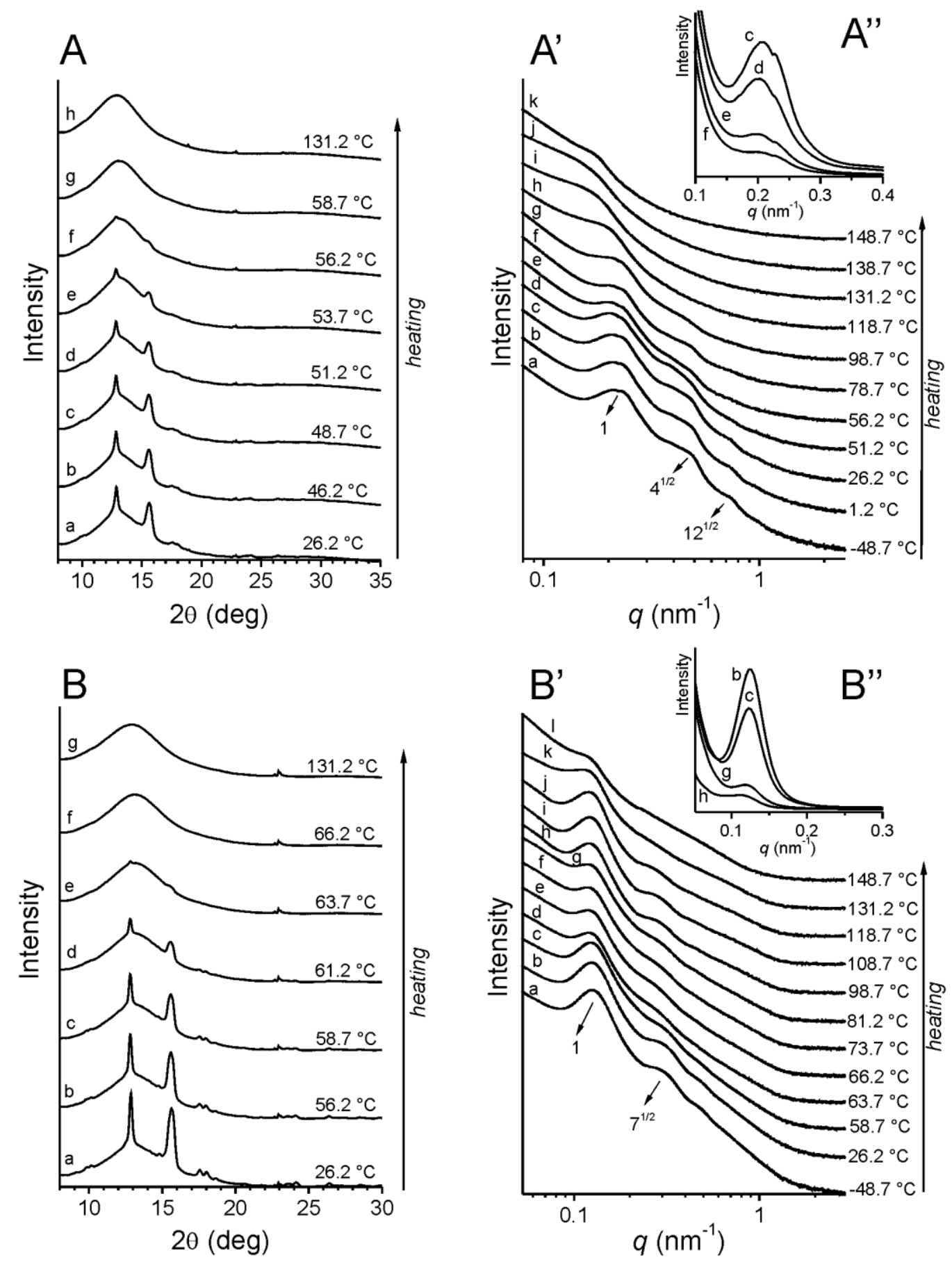

Figure 1. WAXS (A, B) and SAXS (A', B', A', B') profiles of samples SEO (A-A") and HSEO (B-B') recorded at the indicated temperature during the first heating. The arrows in A' and $\mathrm{B}^{\prime}$ indicate the peaks at $q / q_{1} \approx 1,4^{1 / 2}, 7^{1 / 2}, 12^{1 / 2}$ typical of the pseudo-hexagonal morphology. The intensity scale is logarithmic in A', B' and is linear in A', B'. 
At temperatures higher than about $120^{\circ} \mathrm{C}$ (curves h-k of Figure 1A' and k, 1 of Figure 1B') the SAXS peaks disappear indicating a disordered morphology, probably because the order-disorder transition temperature $\left(T_{\mathrm{ODT}}\right)$ of the samples has been reached. In the case of SEO sample, the SAXS profiles recorded at temperature higher than $60{ }^{\circ} \mathrm{C}$ and lower that $T_{\text {ODT }}$ (curves $\mathrm{f}, \mathrm{g}$ of Figure $1 \mathrm{~A}^{\prime}$ ) show only the second order peak at $q / q_{1}=4^{1 / 2}$ of the main reflection at $q_{1} \approx 0.22$ $\mathrm{nm}^{-1}$ due to the increase of packing disorder in the arrangements of PEO cylinders at these temperatures. In the case of HSEO sample, instead, more defined SAXS peaks are observed at temperatures lower than $T_{\mathrm{ODT}}$ and close to the glass transition temperature of PS blocks at $\approx 100$ $110^{\circ} \mathrm{C}$ (curves $\mathrm{h}$ and $\mathrm{i}$ of Figure 1B'), suggesting an improvement of the hexagonal morphology in the melt.

The relative intensity of the main Bragg peak at $q_{1} \approx 0.20 \mathrm{~nm}^{-1}$ for SEO and $0.12 \mathrm{~nm}^{-1}$ for HSEO decreases with increasing temperature especially upon melting of PEO crystals due to decrease of contrast (Figure 1 A', B',).

WAXS and SAXS profiles collected during the cooling from the melt and successive second heating are reported in Figures S2 and S3, respectively. Only the first order reflection peaks are observed ( $q=0.18$ and $0.12 \mathrm{~nm}^{-1}$ for SEO and HSEO, respectively) during cooling (Figure S2), indicating that a not well defined morphology is obtained by cooled from the isotropic melt at a cooling rate of $5^{\circ} \mathrm{C} / \mathrm{min}$.

From the SAXS data collected during the first heating, cooling and second heating scans we have evaluated the reduced scattering invariant $Q$ defined as :

$$
Q=\frac{1}{2 \pi^{2}} \int_{q_{\min }}^{q_{\max }} I(q) q^{2} d q
$$

with $I(q)$ the scattered intensity and $q_{\min }$ and $q_{\max }$ the minimum and maximum values of the scattering vector scanned at low angle. For a biphasic system this parameter is proportional to the 
contrast and to the product of the volume fraction of the two phases. The so obtained $Q$ values and corresponding first derivative are reported in Figures 2A, B and A', B', respectively, as a function of the temperature.
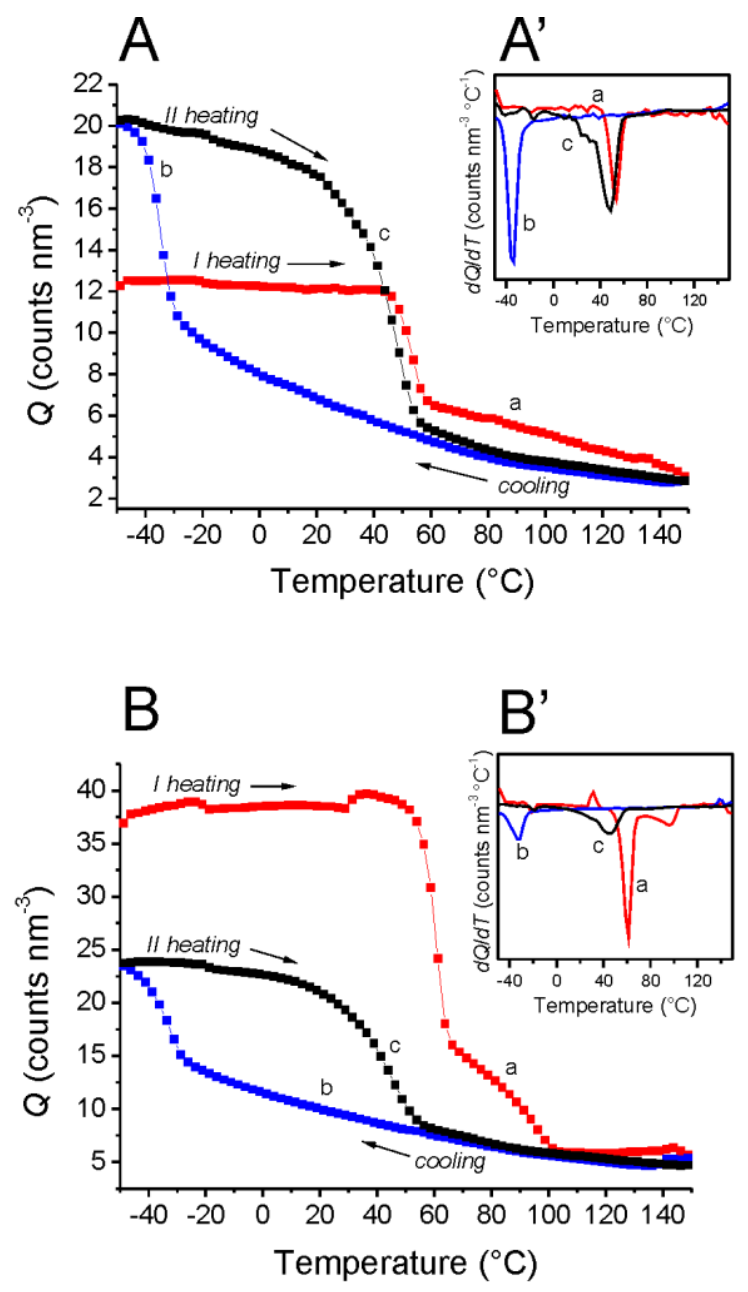

Figure 2. Reduced scattering invariant $(Q)$ as a function of temperature (A, B) and corresponding first derivative (A', B') for the samples SEO (A, A') and HSEO (B, B') calculated from the SAXS data collected during the first heating (a), the cooling (b) and the second heating (c) scans. 
A drop of $Q$ during the first heating (curves a of Figure 2) is observed at $\approx 60{ }^{\circ} \mathrm{C}$ for both SEO and HSEO confirming that the decrease of intensity in SAXS profiles is due to the PEO melting. Similarly, a steep increase crease of $Q$ occurs during cooling at $T \approx-30^{\circ} \mathrm{C}$ (curves b of Figure 2) due to PEO crystallization, followed by a new steep decrease during second heating at $T \approx 40{ }^{\circ} \mathrm{C}$ (curves $\mathrm{c}$ of Figure 2) due to PEO second melting.

It is worth noting that the value of the reduced scattering invariant relative to the first heating scan of HSEO (curve a of Figure $2 \mathrm{~B}$ ) shows a shoulder at $\approx 80-90{ }^{\circ} \mathrm{C}$, that is at temperatures slightly lower than the ordering process occurring at $\approx 100-110{ }^{\circ} \mathrm{C}$ (curves $\mathrm{h}$ and $\mathrm{i}$ of Figure 1B'). This indicates that, after melting of PEO crystals, the ordering process of the nanostructure occurs only after relaxation of the amorphous PS domains at $T_{g}$.

Thin films of neat BCPs and BCP nanocomposites containing Pd precursor. Thin films of neat SEO and HSEO have been prepared by spin-coating dilute solutions (1.5 wt\%) of block copolymers in toluene. Representative FESEM images are reported in Figure 3A and B, respectively. The dark regions correspond to PEO nanodomains and the bright regions to the PS phase. The images denote phase separation in which the PEO blocks form a hexagonal array of perpendicular cylinders in the PS matrix.

The distributions of diameters $(D)$ and center-to-center distances $\left(d_{\mathrm{c}-\mathrm{c}}\right)$ of PEO cylinders are reported in the Figure 3C and D, respectively. Sample SEO shows narrower distributions of size and distances of PEO cylinders than those of HSEO copolymer (Figure 3). The average cylinders diameters are $D_{\mathrm{SEO}} \approx 16 \pm 5 \mathrm{~nm}$ and $D_{\mathrm{HSEO}} \approx 36 \pm 9 \mathrm{~nm}$ (Figure $3 \mathrm{C}$ ), and the average cylinder spacings are $d_{\mathrm{c}-\mathrm{c}(\mathrm{SEO})} \approx 37 \pm 4 \mathrm{~nm}$ and $d_{\mathrm{c}-\mathrm{c}(\mathrm{HSEO})} \approx 74 \pm 10 \mathrm{~nm}$ (Figure 3D), in good agreement with the $d$ values estimated for bulk samples from SAXS data. 

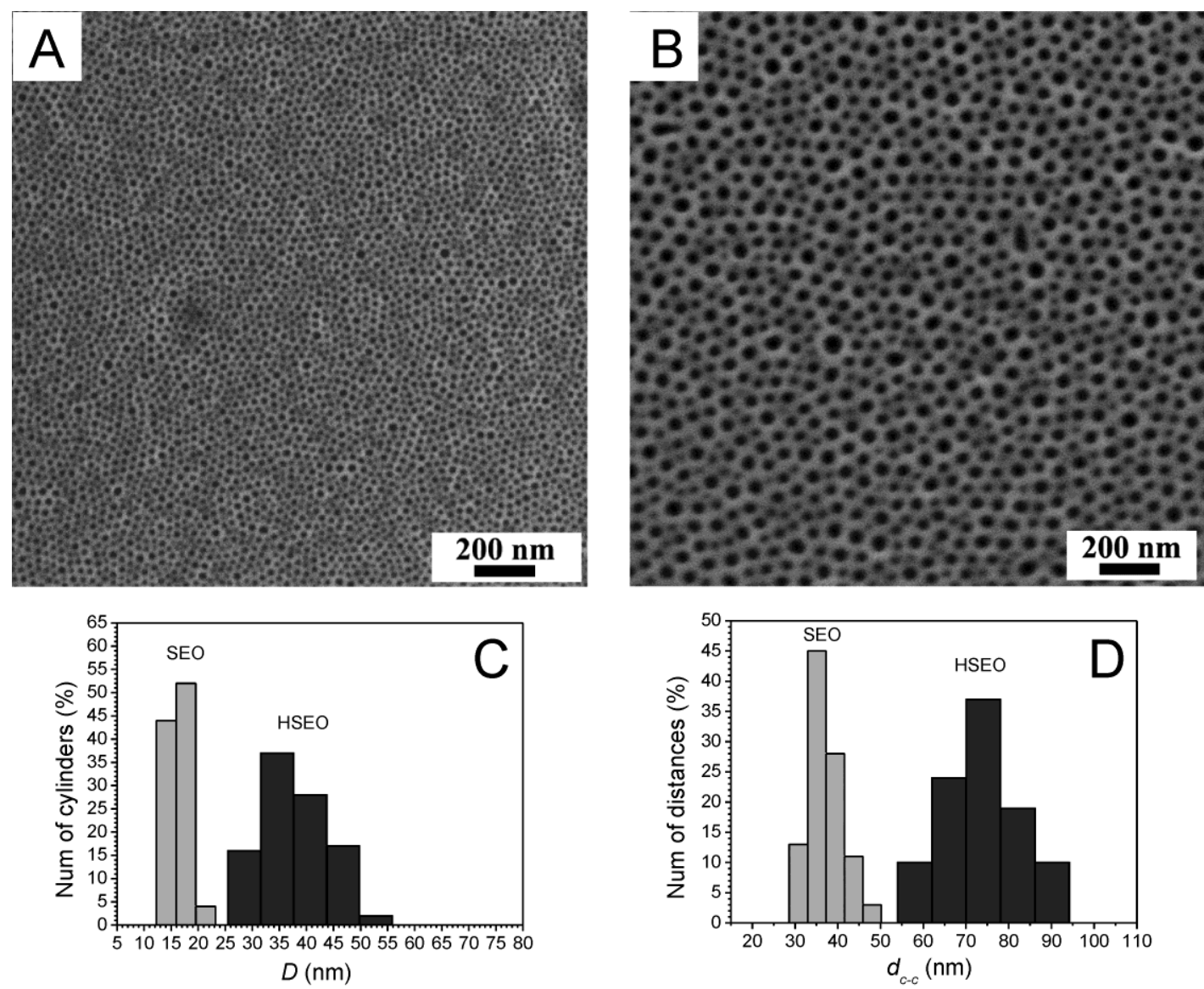

Figure 3. FESEM images of thin films ( $\approx 47 \mathrm{~nm}$ tick) of neat samples SEO (A) and HSEO (B), prepared by spin coating toluene solutions of $\mathrm{BCP}(1.5 \mathrm{wt} \%)$ on silicon wafers, and distribution of the values of diameters $D(\mathrm{C})$ and of the center-to-center distances $d_{\mathrm{c}-\mathrm{c}}(\mathrm{D})$ of PEO cylinders in SEO and HSEO.

Therefore the use of the two different block copolymers with different molecular mass allows controlling the size of the cylindrical domains and domain spacing. The perpendicular orientation of PEO cylinders in both samples (Figure 3) is due both to the high solvent evaporation rate used during the spin-coating process ${ }^{37,38}$ and the comparable thickness of the thin films $(\approx 47 \mathrm{~nm})$ with the domain spacing of both $\operatorname{SEO}\left(d_{\mathrm{c}-\mathrm{c}} \approx 37 \pm 4 \mathrm{~nm}\right)$ and HSEO $\left(d_{\mathrm{c}-\mathrm{c}} \approx\right.$ $74 \pm 10 \mathrm{~nm}$ ) copolymers (Figure 3D). ${ }^{22}$ 
Nanocomposites of BCPs containing palladium nanoparticles have been prepared by using $\operatorname{Pd}(\mathrm{II})$ acetate as precursor of Pd NPs. Thin films of BCPs containing $\operatorname{Pd}(\mathrm{Ac})_{2}$ have been prepared by spin coating of toluene solutions of the BCP $(1.5 \mathrm{wt} \%$ of $\mathrm{BCP})$ and $\mathrm{Pd}(\mathrm{Ac})_{2}(53 \mathrm{wt} \%$ $\mathrm{Pd}(\mathrm{Ac})_{2}$ with respect to the $\mathrm{BCPs}$, corresponding to mole ratio $\mathrm{Pd} / \mathrm{PEO}$ monomeric units equal to $0.40)$.

Representative TEM and FESEM images of thin films of these nanocomposites for SEO and HSEO samples are reported in Figure 4. TEM grids have been observed without resorting to any staining procedure. Therefore, the high contrast between the dark PEO cylinders and the light PS matrix (Figure 4A, B) indicates that the palladium species are not uniformly dispersed in the whole BCP, but they are selectively included in the PEO domains. The palladium precursor, indeed, due to its hydrophilic nature, preferentially interacts with hydrophilic PEO blocks of the BCPs, already in the initial solution. This is confirmed by FESEM images (Figure 4A', B') where the palladium species, selectively included in the PEO domains, appear brighter due to elevation.

The diameter $D$ and the center-to-center distances $d_{c-c}$ of PEO cylinders loaded with Pd species of Figure 4 are $D=17 \pm 5$ and $d_{\mathrm{c}-\mathrm{c}}=35 \pm 9 \mathrm{~nm}$ for SEO (Figure $4 \mathrm{~A}, \mathrm{~A}^{\prime}$ ), and $D=37 \pm 4$ and $d_{\mathrm{c}-\mathrm{c}}$ $=75 \pm 10 \mathrm{~nm}$ for HSEO (Figure 4B, B'). Furthermore, whereas PEO cylinders loaded with $\operatorname{Pd}(\mathrm{Ac})_{2}$ are oriented vertically to the substrate in HSEO (Figure 4B, B'), they are oriented both vertically and parallel to the substrate in SEO (Figure 4A, A'). 

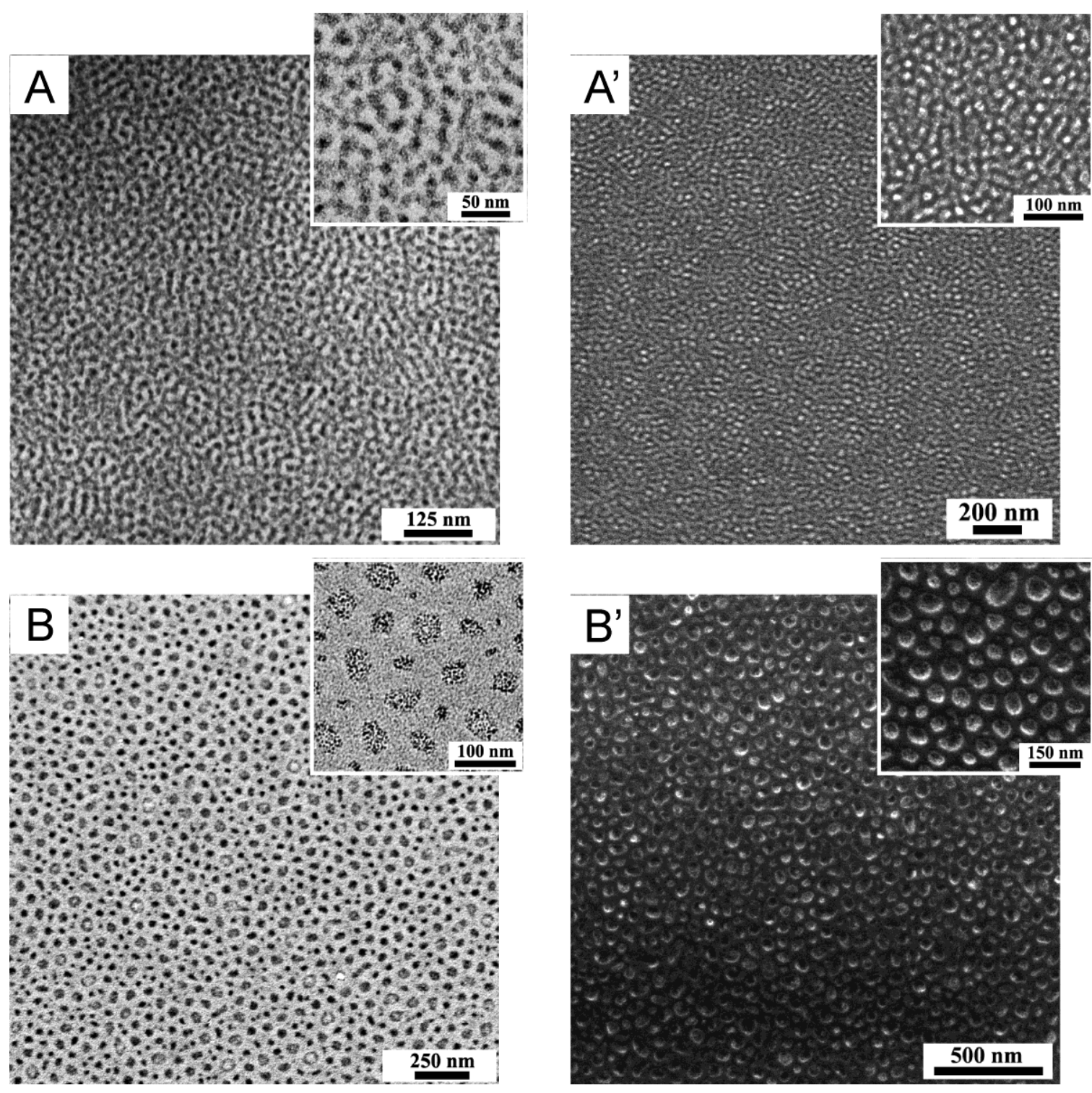

Figure 4. Bright-field TEM (A, B) and FESEM (A',B') images of thin films $(\approx 50 \mathrm{~nm}$ thick $)$ of $\mathrm{BCP}-\mathrm{Pd}(\mathrm{Ac})_{2}$ nanocomposites prepared by spin-coating toluene solutions of samples SEO (A, $\left.\mathrm{A}^{\prime}\right)$ or $\operatorname{HSEO}\left(\mathrm{B}, \mathrm{B}^{\prime}\right)$ and $\mathrm{Pd}(\mathrm{Ac})_{2}\left(53 \mathrm{wt} \%\right.$ of $\mathrm{Pd}(\mathrm{Ac})_{2}$ with respect to the $\left.\mathrm{BCP}\right)$. No staining procedure has employed before the TEM observation.

The thickness of the films containing the palladium precursor $(\approx 50 \mathrm{~nm})$ (Figure 4$)$ is comparable with the domain spacing of both HSEO and SEO copolymer $\left(d_{\mathrm{c}-\mathrm{c}}=35 \pm 9\right.$ and $75 \pm$ $10 \mathrm{~nm}$, respectively). Therefore a perpendicular orientation of PEO cylinders is expected in both 
cases. ${ }^{22}$ However, the less aligned morphology in SEO-Pd nanocomposites may not be due to the smaller diameter of PEO cylinders $(D \approx 16 \pm 5 \mathrm{~nm}$ and $\approx 36 \pm 9 \mathrm{~nm}$ for neat SEO and HSEO, respectively) (Figure 3C). In fact the TEM images of $\mathrm{BCP}-\mathrm{Pd}(\mathrm{Ac})_{2}$ nanocomposites obtained using a lower $\operatorname{Pd}(\mathrm{Ac})_{2}$ concentration in solutions $(26 \mathrm{wt} \%$ with respect to the block copolymers, corresponding to mole ratio $\mathrm{Pd} / \mathrm{PEO}$ monomeric units equal to 0.20) (Figure $\mathrm{S} 4$ ) reveal that also in this case the morphology in the case of SEO (Figure S4A) contains PEO cylinders in the mixed parallel and perpendicular orientation to the substrate. This indicate that the less ordered vertical orientation in the low molecular mass sample SEO may be due to the fact that the segregation strength of PS and PEO domains is not high enough to prevent diffuse interphases at boundaries of interconnected phases domains. For the sample HSEO the high molecular mass gives high the segregation strength and prevents interpenetration.

A different route for fabrication of $\mathrm{BCP} / \mathrm{Pd}$ species nanocomposites has been also tried, consisting in dipping the thin films of neat $\mathrm{BCPs}$ in $\operatorname{Pd}(\mathrm{Ac})_{2}$ solutions with different concentrations for different amount of time. Preliminary data (not shown) indicate inclusion of palladium species in PS domains.

It is worth noting that the electron-irradiation during TEM and FESEM observations can induce the reduction of $\mathrm{Pd}(\mathrm{II})$ salt into $\mathrm{Pd}(0)$ and possibly consequent formation of $\mathrm{Pd}$ nanoparticles. In this way, Pd NPs are obtained in the films but only in a very small area (the observed region). Therefore, a facile route to synthesize $\mathrm{BCP}$ based nanocomposites characterized by selective inclusion of Pd NPs in specific domains has been identified, consisting in the dispersion of a Pd salt in a solution in presence of BCPs, preparation of the thin films and successive electron irradiation. 
BCP nanocomposites with Pd nanoparticles. An alternative and more efficient route to prepare BCP nanocomposites containing Pd NPs has also been used. After addition of $\operatorname{Pd}(\mathrm{Ac})_{2}$ to the BCPs solutions, the mixtures have been heated at $75^{\circ} \mathrm{C}$ in a water bath under vigorous and continuous stirring. The yellow color of the initial solution becomes brown and finally gray dark, indicating the formation of Pd NPs (Figure 5A').

The reduction of $\mathrm{Pd}(\mathrm{II})$ ions to $\mathrm{Pd}(0)$ has been followed by recording $\mathrm{UV}$-visible spectra of the solution before and after during heating at $75^{\circ} \mathrm{C}$ (Figure $\left.5 \mathrm{~A}\right)$. The initial toluene solution $(1 \mathrm{~mL})$ containing the $\mathrm{BCP}(1.5 \mathrm{wt} \%)$ and the palladium precursor (26 wt\% with respect to $\mathrm{BCP}$ ) has been diluted by adding $2 \mathrm{~mL}$ of toluene and then UV-Vis spectra of Figure $5 \mathrm{~A}$ have been recorded. The initial solution shows absorption maximum at around $400 \mathrm{~nm}$, which is characteristic of $\mathrm{Pd}(\mathrm{II})$ ions (curve a of Figure 5A). The peak completely disappears after around 5h heating at $75{ }^{\circ} \mathrm{C}$ (curve $\mathrm{d}$ of Figure 5A), and no new plasmon absorption maximum are shown, in good agreement with the complete conversion of $\operatorname{Pd}(\mathrm{II})$ to $\operatorname{Pd}(0)$ species. Therefore, heating of the solution containing the $\mathrm{BCP}$ and the palladium precursor results in the direct formation of $\operatorname{Pd}(0)$ species in presence of $\mathrm{BCP}$ before thin film preparation. Since data of Figure 4 have indicated infiltration of $\mathrm{Pd}(\mathrm{Ac})_{2}$ into PEO cylinders, the reduction of $\mathrm{Pd}(\mathrm{II})$ species to $\operatorname{Pd}(0)$ occurs into PEO cylinders and, according to the literature, ${ }^{39,} 40$ leads, in presence of PEO, to formation of nanoparticles. This process is assisted by PEO chains, which, in absence of other chemical agents, may act both as reducing agent and stabilizer, preventing aggregation.

The required reaction time depends on the temperature, as demonstrated in Figure S5 that shows from the color of the solutions heated at 75 and $85^{\circ} \mathrm{C}$ a lower reaction time needed at higher temperature. 


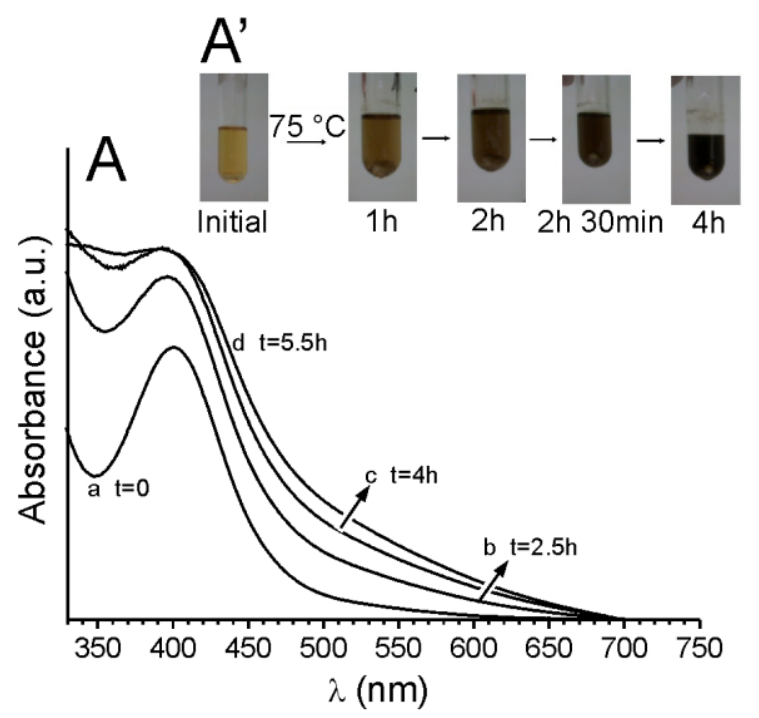

Figure 5. (A) UV-visible spectrum of a toluene solution containing HSEO (1.5 wt $\%)$ and $\mathrm{Pd}(\mathrm{Ac})_{2}(26 \mathrm{wt} \%$ with respect to the $\mathrm{BCP})(\mathrm{a})$ and of the same solution after heating at $75^{\circ} \mathrm{C}$ for $2.5 \mathrm{~h} \mathrm{(b),} 4 \mathrm{~h}(\mathrm{c})$ and $5.5 \mathrm{~h}(\mathrm{~d}) .2 \mathrm{~mL}$ of toluene have been added to $1 \mathrm{~mL}$ of the initial solution before recording the UV-Vis spectra. A') Photographs of the toluene solution containing HSEO and $\operatorname{Pd}(\mathrm{Ac})_{2}$ during heating at $75^{\circ} \mathrm{C}$ for the indicated times.

Thin films of BCP nanocomposites containing Pd NPs (BCP-PdT) have been prepared by spin coating solutions containing the BCPs and the Pd NPs produced by heat treatment at $85{ }^{\circ} \mathrm{C}$ for at least $3 \mathrm{~h}$. TEM and FESEM images of these films of BCP-PdT are shown in Figure 6.

Also in this case the dark spots in TEM and bright spots in FESEM correspond to Pd NPs. It is apparent that most of Pd species forms Pd NPs confined inside PEO cylinders, even though part of Pd species gives rise by effect of heating to independent nanoparticles not included into the BCP template. Therefore, the microphase separation of the PS- $b$-PEO directs the spatial distribution of nanoparticles, which result confined in narrow regions and periodically distributed within the microstructure. 

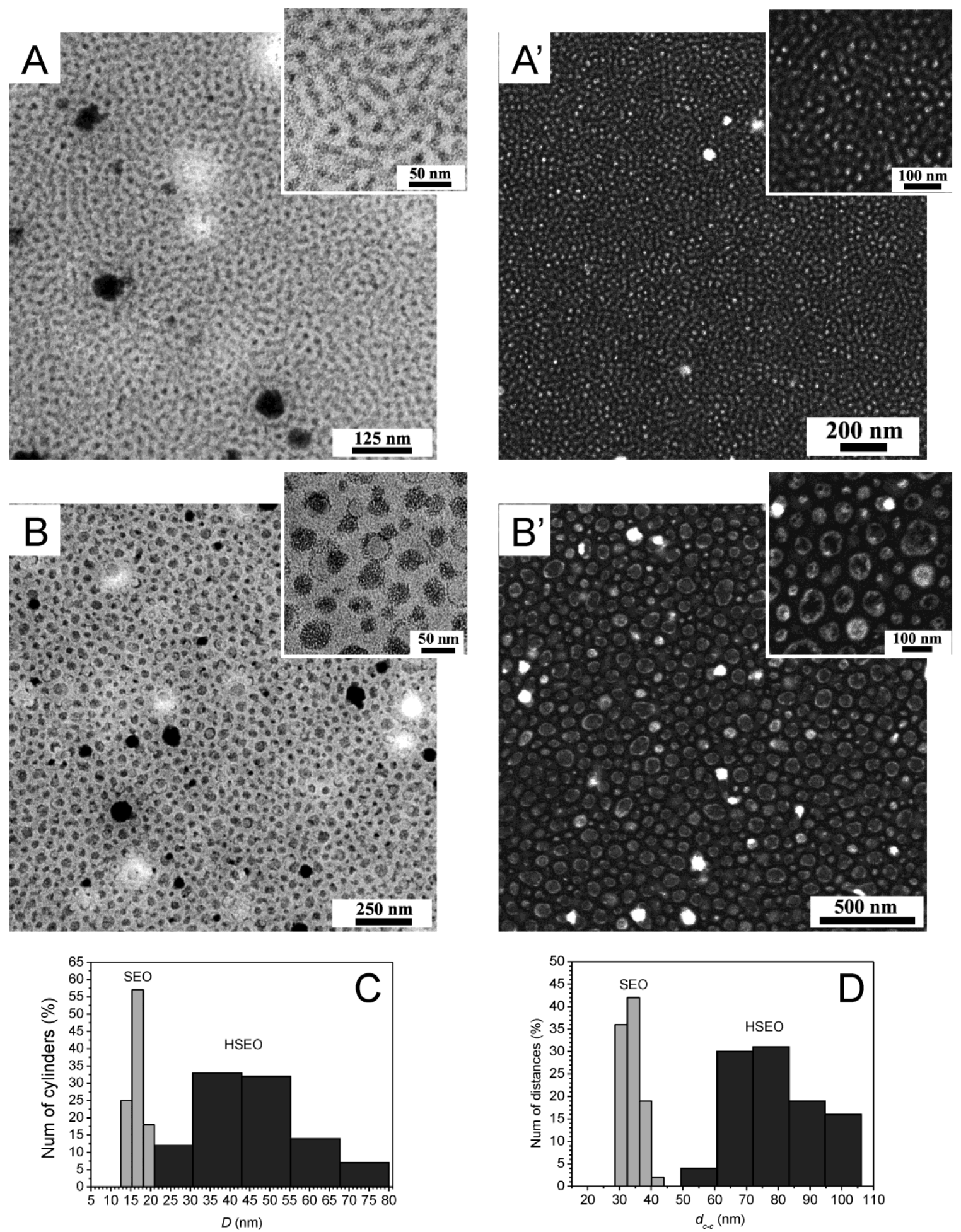

Figure 6. Bright-field TEM (A, B) and FESEM (A', B') images of thin films $(\approx 60 \mathrm{~nm}$ thick) of BCP-PdT nanocomposites prepared by spin-coating a toluene solution of samples SEO (A,A') or 
HSEO (B,B') and Pd NPs and distribution of the values of diameters $D(\mathrm{C})$ and of the center-tocenter distances $d_{c-c}$ (D) of PEO cylinders containing Pd NPs in SEO and HSEO. The Pd NPs have been prepared by heating at $85^{\circ} \mathrm{C}$ a $1.5 \mathrm{wt} \%$ toluene solution of SEO (A, A') and HSEO (B, B') containing $\mathrm{Pd}(\mathrm{Ac})_{2}(\approx 53 \mathrm{wt} \%$ with respect to the $\mathrm{BCP})$ resulting in the reduction of $\mathrm{Pd}(\mathrm{II})$ ions in solution. No staining procedure has employed before the TEM observation.

To confirm the BCPs role in directing the distribution of NPs, we have repeated the same procedure for preparation of $\mathrm{BCP}$ nanocomposites of Figure 6 using a PEO homopolymer (molecular mass 20000) as polymeric matrix. In this case, only large Pd aggregates are formed, as shown by TEM image of Figure S6.

The distribution of diameters $(D)$ and center-to-center distances $\left(d_{c-c}\right)$ of PEO domains, evaluated from FESEM images of Figure 6A' and B', are reported in Figure 6C and D, respectively. The average PEO-Pd cylinder diameters and the average center-to-center distances of PEO domains are $D_{\mathrm{SEO}} \approx 17 \pm 4, D_{\mathrm{HSEO}} \approx 40 \pm 10 \mathrm{~nm}$ (Figure $6 \mathrm{C}$ ), and $d_{\mathrm{c}-\mathrm{c}(\mathrm{SEO})} \approx 35 \pm 5 \mathrm{~nm}$, $d_{\mathrm{c}-\mathrm{c}(\mathrm{HSEO})} \approx 75 \pm 10 \mathrm{~nm}$ (Figure $6 \mathrm{D}$ ), similar to those obtained in the case of neat BCPs (Figure 3C and D). Moreover, for HSEO larger distributions are obtained for both the diameters and center-to-center distances (Figure 6 C, D).

The use of the BCPs with different chain lengths has allowed controlling the dimensions and the distances between PEO cylinders and, consequently, to obtain BCP-PdT nanocomposites characterized by Pd nanoclusters placed in domains of controlled average size and distances, similar to those of parent BCP nanostructures.

The effective presence of $\operatorname{Pd}(0)$ NPs has been probed using our BCP-PdT nanocomposites as catalyst for palladium-catalyzed Suzuki cross-coupling reaction of an aryl halide (4bromoanisole) with phenylboronic acid (Scheme 1). 
Scheme 1. Reaction between the 4-bromoanisole and the phenylboronic acid, catalyzed by Pd NPs in the presence of a base (potassium carbonate).
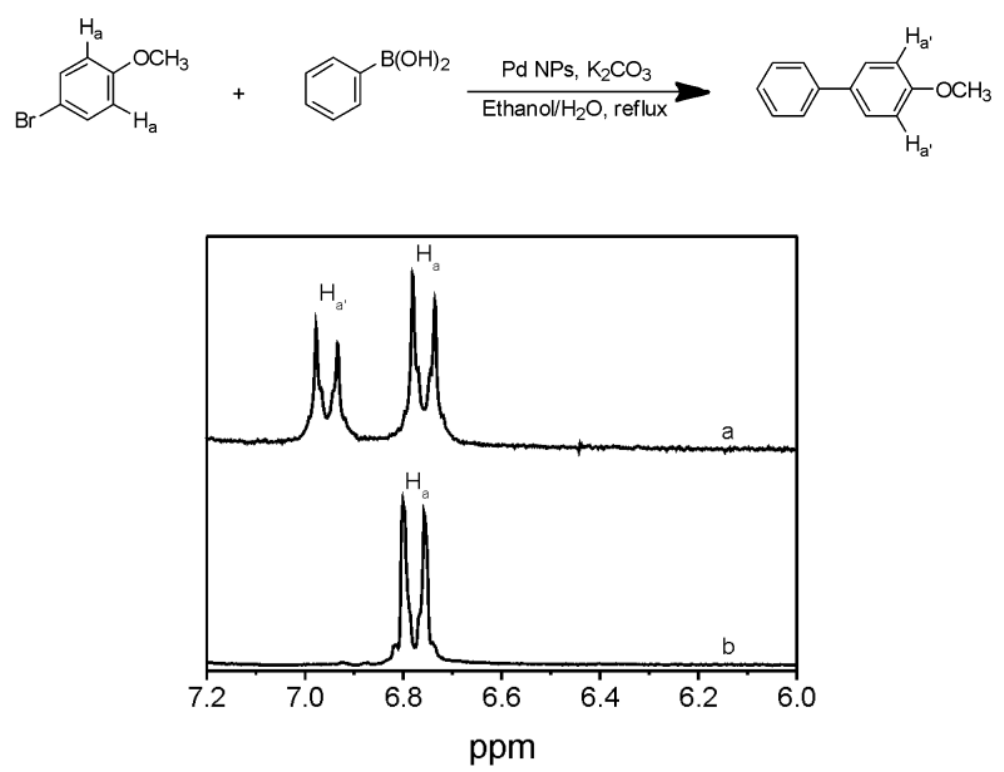

Figure 7. ${ }^{1} \mathrm{H}$ NMR spectrum of the mixture obtained after $1 \mathrm{~h}$ reaction of scheme 1 between the 4-bromoanisole and the phenylboronic acid in presence of thin films of BCP-PdT (a) and neat BCP (b). The signal at $6.95 \mathrm{ppm}\left(\mathrm{H}_{\mathrm{a}}{ }^{\prime}\right)$ confirms the presence of the product of Suzuki reaction. The signal at $6.75 \mathrm{ppm}\left(\mathrm{H}_{\mathrm{a}}\right)$ is due to the proton of unreacted 4-bromoanisole. $\mathrm{CHCl}_{3}(\delta=7.26$ ppm respect to TMS) has been used as internal standard.

The reaction of Scheme 1 has been carried out placing the thin film of BCP-PdT nanocomposite (prepared on a glass substrate) into a flask containing the solvent ethanol/water and the others reagents (4-bromoanisole, phenylboronic acid and the base potassium carbonate, see experimental part for details). The thin films of BCP-PdT nanocomposite used for the reaction have been washed with the same solvent used for the reaction (1/1 volume ratio ethanol/water) for 2-3 times before immersing the substrate into reaction flask. 
The ${ }^{1} \mathrm{H}$ NMR spectrum of the solid product obtained after $1 \mathrm{~h}$ reaction is reported in Figure 7 (curve a). The NMR signal at $6.9 \mathrm{ppm}$ confirms the presence of the Suzuki reaction product, giving an indirect proof of the presence of Pd NPs in our thin films. We have verified that use of thin film of neat $\mathrm{BCP}$ does not give Suzuki cross-coupling reaction under the same reaction conditions used for the BCP-PdT substrate (curve b of Figure 7).

Preparation of PdO nanoparticles onto silicon substrates. Thin films of BCP-PdT nanocomposites containing SEO or HSEO and Pd nanoparticles (Figure 6), prepared on silicon substrates, have been heated at $600{ }^{\circ} \mathrm{C}$ in air for $4 \mathrm{~h}$. The thermogravimetric analysis (TGA) of the HSEO block copolymer (Figure S7) shows that at $\approx 460{ }^{\circ} \mathrm{C}$ degradation of the $\mathrm{BCP}$ is almost complete. This indicates that the $600^{\circ} \mathrm{C}$ heat treatment of BCP-PdT nanocomposites produces complete removal of the polymeric matrix. At this temperature, the formation of $\mathrm{PdO}$ nanoparticles is also expected. ${ }^{41,42}$ Therefore, the treatment of our BCP-PdT nanocomposites leaves PdO nanoparticles on the solid and conductive support.

FESEM images of the so obtained silicon supports covered by PdO NPs are reported in Figure $8 \mathrm{~A}, \mathrm{~B}$. The distribution of the size $(S)$ and center-to-center distance $\left(d_{c-c}\right)$ of the so obtained $\mathrm{PdO}$ NPs are reported in Figure 8C and D, respectively.

The average size $S$ and the average center-to-center distance $d_{\text {c-c }}$ of PdO NPs are $S \approx 17 \pm 5 \mathrm{~nm}$ and $d_{\mathrm{c}-\mathrm{c}} \approx 37 \pm 9$ for the $\mathrm{PdO}$ nanoparticles obtained after the removal of the polymeric matrix SEO, and $S \approx 34 \pm 9 \mathrm{~nm}$ and $d_{\mathrm{c}-\mathrm{c}} \approx 74 \pm 12 \mathrm{~nm}$ for the PdO nanoparticles obtained using the HSEO block copolymer as template (Figure $8 \mathrm{C}, \mathrm{D})$. The obtained values well match the average diameters and the center-to-center distances of the corresponding PEO cylinders in the BCPs used as template (Figure 3) and in the corresponding nanocomposites (Figure 6). Therefore, after 
the polymer removal the resulting PdO NPs maintain the same size and spacing of the PEO cylinders in the parent block copolymers (Figure 3).
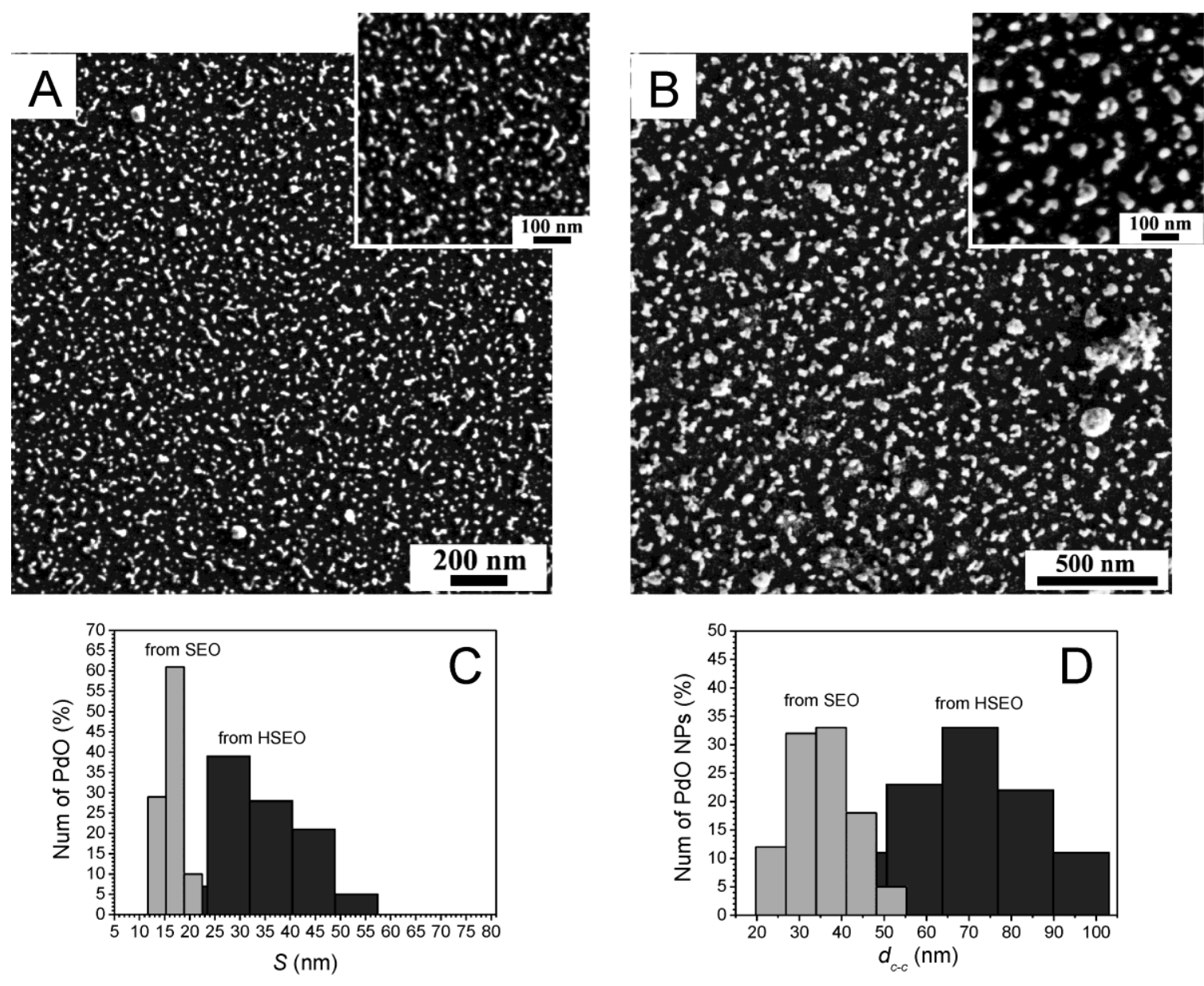

Figure 8. FESEM images of $\mathrm{PdO}$ nanoparticles on silicon wafers obtained after the oxidative treatment at $460{ }^{\circ} \mathrm{C}$ of thin films of BCP-PdT nanocomposites of Figure 6 containing Pd NPs into PEO cylinders of SEO (A) and HSEO (B). The surface coverage is $\approx 562$ and $\approx 245$ nanoclusters $/ \mu \mathrm{m}^{2}$ in the case of PdO nanoclusters obtained by using SEO and HSEO as template, respectively. Distribution of the values of the size $S(\mathrm{C})$ and of the center-to-center distance $d_{\mathrm{c}-\mathrm{c}}$ (D) of the obtained PdO NPs using SEO and HSEO as template.

These data indicate that the use of the two BCPs with different chain lengths allows controlling the dimensions and the distances between microdomains and, consequently, obtaining arrays of 
PdO NPs on a solid support characterized by tailored NPs diameter and gap distance, mirroring the pattern and the characteristic nanodimensions of the parent block copolymer template.

The presence of metallic Pd in our BCP-PdT nanocomposites and PdO NPs on the silicon support after removal of $\mathrm{BCP}$ has been confirmed by grazing incidence wide angle scattering (GIWAXS) experiments. Two dimensional GIWAXS images of our HSEO-PdT nanocomposite and silicon supports covered by PdO NPs obtained after the heat treatment are reported in Figure S8. The corresponding intensities read along the vertical cuts (indicated by red lines in Figure S8) are reported in Figure 9.

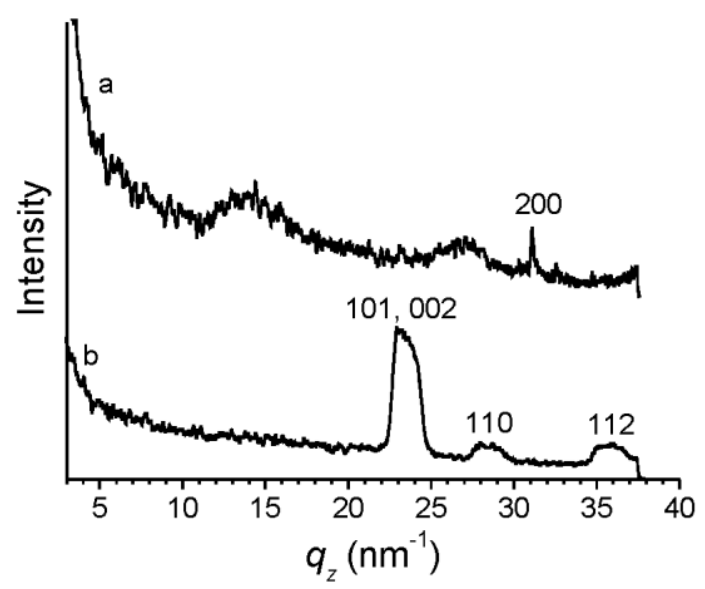

Figure 9. Vertical GIWAXS profiles of thin films of HSEO-PdT nanocomposite (a) and of PdO NPs on the silicon support (b). Profiles have been obtained from cuts of the bidimensional GIWAXS pattern of Figure S8 taken along the vertical red lines. $q$ is the modulus of the scattering vector, $q=4 \pi \sin \theta / \lambda$ with $\lambda=1.033 \AA$ the used radiation wavelength and $\theta$ the halved angle between the incident and the scattered beam in the vertical direction.

A reflection peak is visible at $q \approx 31 \mathrm{~nm}^{-1}$ (curve a of Figure 9), corresponding to the 200 reflection of Pd at $d \approx 0.20 \mathrm{~nm}^{43}$ The absence of 111 reflection of Pd at $q \approx 28 \mathrm{~nm}^{-1}(d \approx 0.22$ $\mathrm{nm}$ ) and the uniform intensity of 200 reflection along a circle in the bi-dimensional pattern of 
Figure S8A indicate that Pd crystals lay with the 200 plane parallel to the silicon support. In the GIWAXS profile of silicon supports covered by PdO nanoparticles (curve b of Figure 9), the $002,101,110$ and 112 reflection peaks of $\mathrm{PdO}$ at $d \approx 0.27,0.26,0.22$ and $0.17 \mathrm{~nm}$ are clearly apparent. They correspond to the most intense reflections of tetragonal crystals of $\mathrm{PdO}$ in the sampled range. ${ }^{44}$ The uniform intensity distribution of the reflection along circles in Figure S8B indicates that the orientation of $\mathrm{PdO}$ nanocrystals is random.

The morphologies of thin films of neat HSEO, and nanocomposites HSEO-Pd(Ac) $)_{2}$, HSEOPdT and PdO NPs on the silicon support have also been investigated via Gracing Incidence Small Angle X-ray scattering (GISAXS). GISAXS image of the HSEO thin film (Figure 10A) is in agreement with cylindrical morphology and vertically oriented cylinders, with average lateral cylinder-cylinder distance of $77 \mathrm{~nm}$, calculated using the Bragg law from the maximum in the $q_{y}$ cut located at $q=0.082 \mathrm{~nm}^{-1}$ (Figure $10 \mathrm{D}$ ). This value is in excellent agreement with FESEM data (Figure 3B). Incorporation of the $\mathrm{PdAc}_{2}$ and Pd NPs inside the PEO domains for the samples HSEO-Pd(Ac) $)_{2}$ (Figure $10 \mathrm{~B}$ ) and HSEO-PdT (Figure $10 \mathrm{C}$ ) causes an increase of the scattering intensity. At low angles, the signal related to the inter-cylinder spacing is now less clear due to the increased disorder in the nanocomposites including Pd species (compare Figures 3B, 4B,B' and 6B,B'). At high in-plane angles $\left(q_{y}>0.2 \mathrm{~nm}^{-1}\right)$, the scattering of the HSEO-PdT sample is dominated by the signal from the Pd NPs. Assuming that the NPs are spherical in shape, the data can be fitted using a unified model adapted to the GISAXS geometry. ${ }^{27-29}$ The average dimension for the Pd NPs inside the PEO domains as calculated from the unified model is $4 \mathrm{~nm}$. GISAXS data for the PdO particles obtained by heat treatment at $600{ }^{\circ} \mathrm{C}$ are in agreement with scattering from $\mathrm{PdO}$ nanoparticles supported on the Si substrate with tendency to assemble in larger aggregates, as denoted by excess of scattering in the low angle region. The 
average PdO NPs lateral dimension calculated by the unified model fit is about $8 \mathrm{~nm}$, whereas the average dimension for the PdO aggregates is about $27 \mathrm{~nm}$, in good agreement with FESEM results (Figure 8C).
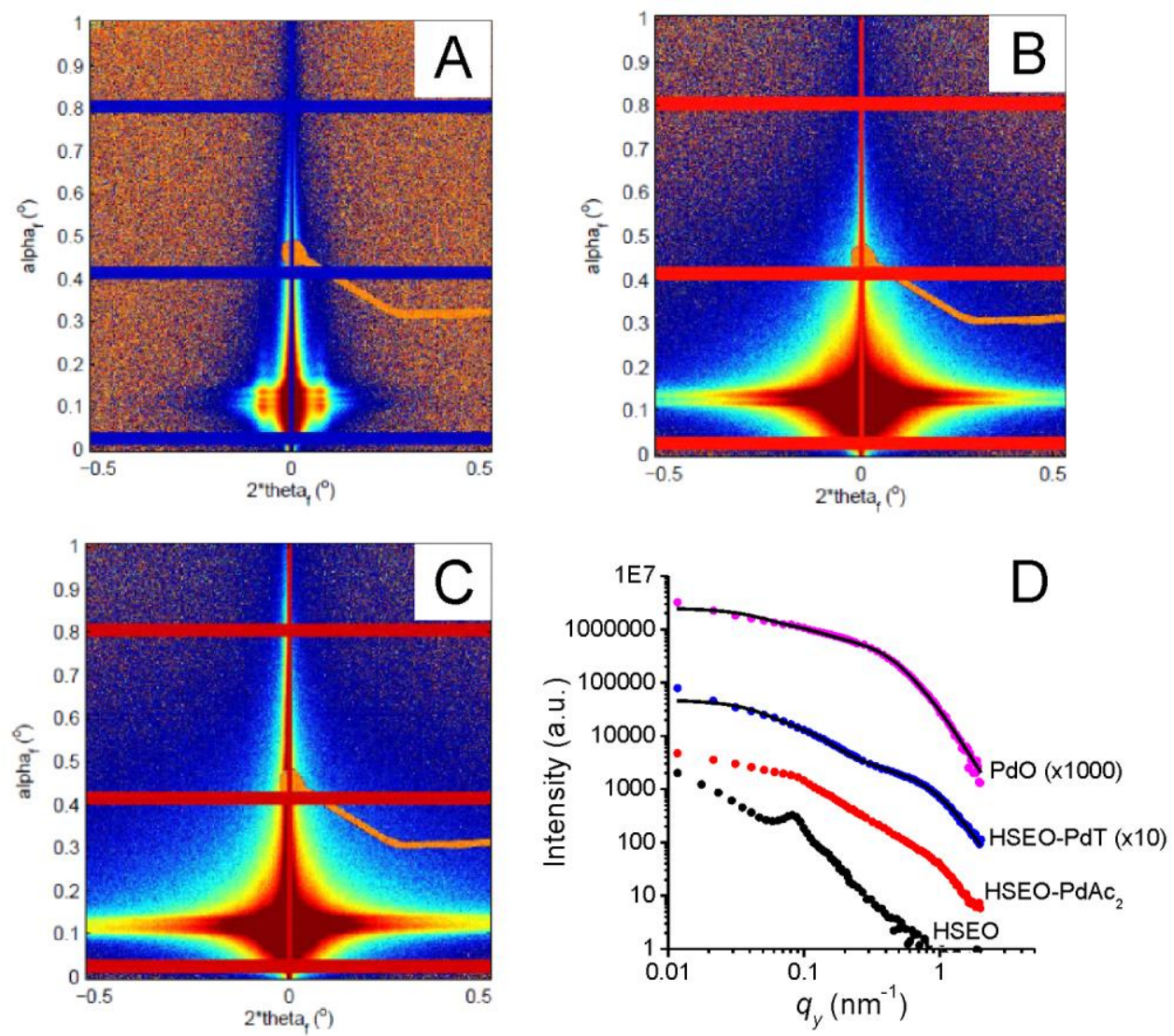

Figure 10. GISAXS images of thin films of neat HSEO (A), HSEO-Pd(Ac) $)_{2}(\mathrm{~B})$ and HSEO-PdT (C) and corresponding horizontal GISAXS profiles for HSEO, HSEO-PdAc 2 , HSEO-PdT and PdO on silicon (D). Bi-dimensional GISAXS image of PdO is reported in Figure S9. Profiles in D have been obtained from cuts of the images taken at the Yoneda peak height. The same incident angle $\alpha_{i}=0.46^{\circ}\left(>>\alpha_{c}\right)$ has been used for all the samples. Solid lines represent the best fits. 


\section{CONCLUSIONS}

In this work we have reported a simple and cost effective process for the pattering of a thin film surface with Pd NPs and for tuning the characteristic size (diameter and lateral spacing) of Pd nanoclusters and PdO nanoparticles on solid supports. We have selected two samples of PS$b$-PEO block copolymers having different molecular mass as templates, because of the favorable interaction of $\mathrm{PEO}$ blocks with the salt $\mathrm{Pd}(\mathrm{Ac})_{2}$ used as precursor of $\mathrm{Pd}$ species. Pd nanoparticles have been produced by reduction of $\mathrm{Pd}(\mathrm{II})$ ion in the presence of $\mathrm{BCPs}$, without disturbing the regular microdomain structure of block copolymers. The resulting nanocomposite thin films show the metal Pd nanoparticles selectively included in cylindrical PEO nanodomains, with a nanoclusters average diameter and gap distance mirroring the parent $\mathrm{BCP}$ used as template. The treatment of the nanocomposites at elevated temperatures in air removes the $\mathrm{BCP}$ matrix and leads to the formation of arrays of PdO NPs covering a solid support. The average diameter and the center-to-center spacing are still maintained. This work confirms that the ability to control the length, the spatial distribution and orientational organization of block-copolymer morphologies makes these materials particularly attractive as scaffolds for engineering of ordered nanocomposites in which the distribution of the guest particles is guided by the ordering of the host matrix. The ability to create morphologically and dimensionally controlled Pd and PdO nanoparticles would be the key point in the process of transforming these systems from promising materials into integrated devices and the compatibility of these systems with the existing silicon-based technology makes them even more attractive.

\section{ASSOCIATED CONTENT}

Supporting Information. DSC curves of block copolymers. Table listing SAXS peak positions and $d$-spacings observed in the SAXS profiles of block copolymers recorded during heating. 
WAXS and SAXS profiles of block copolymers recorded during cooling from the melt and during the second heating after crystallization from the melt. TEM images of thin films of BCP$\operatorname{Pd}(\mathrm{Ac})_{2}$ nanocomposites prepared by spin-coating toluene solutions of samples SEO or HSEO and $\mathrm{Pd}(\mathrm{Ac})_{2}$ at concentration of $26 \mathrm{wt} \%$ of $\mathrm{Pd}(\mathrm{Ac})_{2}$ with respect to the $\mathrm{BCP}$. Photographs of the initial toluene solution containing $\mathrm{HSEO}$ and $\mathrm{Pd}(\mathrm{Ac})_{2}$ and of the same solution after heating at $75^{\circ} \mathrm{C}$ and $85^{\circ} \mathrm{C}$. TEM image of thin films of PEO-Pd nanocomposites. TGA curve of the HSEO block copolymer. Two dimensional GIWAXS pattern of thin films of HSEO-PdT nanocomposites and of silicon support covered by PdO NPs. Bi-dimensional GISAXS image of PdO on silicon support. This material is available free of charge via the Internet at http://pubs.acs.org.

\section{AUTHOR INFORMATION}

\section{Corresponding Author}

*E-mail: anna.malafronte@unina.it. Phone: ++39081674309.

\section{Notes}

The authors declare no competing financial interest.

\section{ACKNOWLEDGMENT}

Financial support from the Ministero dell'Istruzione, dell'Università e della Ricerca of Italy (FIRB project, Design of nano-heterogeneous materials for solar energy conversion) is gratefully acknowledged. M.L. and M.N.S. thank the financial support by the Spanish Ministerio de Educación, Cultura y Deporte (MAT2012-36754-C02-01) and the Xunta de Galicia (GRC2013044 FEDER funds). We thank Prof. Francesco Ruffo and Dr. Matteo Lega of the University of 
Naples Federico II for the assistance in performing the Suzuki cross-coupling experiments and for the useful discussion.

\section{REFERENCES}

(1) Altavilla, C.; Ciliberto, E. Inorganic nanoparticles: synthesis, applications, and perspectives; CRC Press: Boca Raton, FL, 2011.

(2) Liao, J.; Blok, S.; van der Molen, S. J.; Diefenbach, S.; Holleitner, A. W.; Schönenberger, C.; Vladyka, A.; Calame, M. Ordered nanoparticle arrays interconnected by molecular linkers: electronic and optoelectronic properties. Chem. Soc. Rev. 2015, 44, 999-1014.

(3) Langhammer, C.; Yuan, Z.; Zoric, I.; Kasemo, B. Plasmonic properties of supported Pt and Pd nanostructures. Nano Lett. 2006, 6, 833-838.

(4) Deng, W.; Goldys, E. M. Chemical sensing with nanoparticles as optical reporters: from noble metal nanoparticles to quantum dots and upconverting nanoparticles. Analyst 2014, 139, 5321-5334.

(5) Guidez, E. B.; Aikens, C. M. Quantum mechanical origin of the plasmon: from molecular systems to nanoparticles. Nanoscale 2014, 6, 11512-11527.

(6) Balanta, A.; Godard, C.; Claver, C. Pd nanoparticles for C-C coupling reactions. Chem. Soc. Rev. 2011, 40, 4973-4985.

(7) Nicolaou, K. C.; Bulger, P. G.; Sarlah, D. Palladium-catalyzed cross-coupling reactions in total synthesis. Angew. Chem. Int. Ed. 2005, 44, 4442-4489.

(8) Astruc, D.; Lu, F.; Aranzaes, J. R. Nanoparticles as recyclable catalysts. The frontier between homogeneous and heterogeneous catalysis. Angew. Chem. Int. Ed. 2005, 44, 7852-7872. 
(9) Ozawa, Y.; Tochihara, Y.; Nagai, M.; Omi, S. PdO/ $\mathrm{Al}_{2} \mathrm{O}_{3}$ in catalytic combustion of methane: stabilization and deactivation. Chem. Eng. Sci. 2003, 58, 671-677.

(10) McCarty, J. G. Kinetics of PdO combustion catalysis. Catal. Today 1995, 26, 283-293.

(11) Stuchinskaya, T. L.; Kozhevnikov, I. V. Liquid-phase oxidation of alcohols with oxygen catalysed by modified palladium(II) oxide. Catal. Commun. 2003, 4, 417-422.

(12) Shendage, S. S.; Patil, U. B.; Nagarkar, J. M. Electrochemical synthesis and characterization of palladium nanoparticles on nafion-graphene support and its application for Suzuki coupling reaction. Tetrahedron Lett. 2013, 54, 3457-3461.

(13) Adams, B. D.; Chen, A. The role of palladium in a hydrogen economy. Mater. Today 2011, 14, 282-289.

(14) Zeng, X. Q.; Latimer, M. L.; Xiao, Z. L.; Panuganti, S.; Welp, U.; Kwok, W. K.; Xu, T. Hydrogen Gas Sensing with Networks of Ultrasmall Palladium Nanowires Formed on Filtration Membranes. Nano Lett. 2011, 11, 262-268.

(15) Santhanam, V.; Andres, R. P. Microcontact Printing of Uniform Nanoparticle Arrays. Nano Lett. 2004, 4, 41-44.

(16) Rabani, E.; Reichman, D. R.; Geissler, P. L.; Brus, L. E. Drying-mediated self-assembly of nanoparticles. Nature 2003, 426, 271-274.

(17) Bockstaller, M. R.; Mickiewicz, R. A.; Thomas, E. L. Block copolymer nanocomposites: Perspectives for tailored functional materials. Adv. Mater. 2005, 17, 1331-1349. 
(18) De Rosa, C.; Auriemma, F.; Di Girolamo, R.; Pepe, G. P; Napolitano, T.; Scaldaferri, R. Enabling Strategies in Organic Electronics Using Ordered Block Copolymer Nanostructures. Adv. Mater. 2010, 22, 5414-5419.

(19) Li, Z.; Sai, H.; Warren, S. C.; Kamperman, M.; Arora, H.; Gruner, S. M.; Wiesner, U. Metal Nanoparticle-Block Copolymer Composite Assembly and Disassembly. Chem. Mater. 2009, 21, 5578-5584.

(20) Bates, F. S.; Fredrickson, G. H. Block copolymer thermodynamics: theory and experiment. Annu. Rev. Phys. Chem. 1990, 41, 525-557.

(21) Hamley, I. W. The Physics of Block Copolymers; Oxford University Press: Oxford, 1998.

(22) Fasolka, M. J.; Mayes, A. M. Block copolymer thin films: physics and applications. Annu. Rev. Mater. Res. 2001, 31, 323-325.

(23) Lazzari, M.; De Rosa, C. In Advanced Nanomaterials; Geckeler, K.E., Nishide, H.; Wiley-vch: Weinheim, 2009; Chapter 4, pp 111-158.

(24) Hadjichristidis, N.; Pitzikalis, M.; Pispas, S.; Iatrou H. Polymers with Complex Architecture by Living Anionic Polymerization. Chem. Rev. 2001, 101, 3747-3792.

(25) Bras, W. An SAXS/WAXS beamline at the ESRF and future experiments. J. Macromol. Sci. B 1998, 37, 557-565.

(26) Portale, G.; Cavallo, D.; Alfonso, G. C.; Hermida-Merino, D.; van Drongelen, M.; Balzano, L.; Peters, G. W. M.; Goossens, J. G. P.; Bras, W. Polymer crystallization studies under processing-relevant conditions at the SAXS/WAXS DUBBLE beamline at the ESRF. J. Appl. Cryst. 2013, 46, 1681-1689. 
(27) Beaucage, G. Approximations leading to a unified exponential/power-law approach to small-angle scattering. J. Appl. Crystallogr. 1995, 28, 717-728.

(28) Beaucage, G. Small-angle scattering from polymeric mass fractals of arbitrary massfractal dimension. J. Appl. Crystallogr. 1996, 29, 134-146.

(29) Lenz, S.; Bonini, M.; Nett, S. K.; Memesa, M.; Lechmann, M. C.; Emmerling, S. G. J.; Kappes, R. S.; Timmann, A.; Roth, S. V.; Gutmann, J. S. Global scattering functions: a tool for grazing incidence small angle X-ray scattering (GISAXS) data analysis of low correlated lateral structures. Eur. Phys. J. - Appl. Phys. 2010, 51, 10601.

(30) Portale, G.; Sciortino, L.; Albonetti, C.; Giannici, F.; Martorana, A.; Bras, W.; Biscarini, F.; Longo, A. Influence of metal-support interaction on the surface structure of gold nanoclusters deposited on native $\mathrm{SiO}$ x/Si substrates. Phys Chem Chem Phys 2014, 16, 6649-6656.

(31) Grulke, E. A.; Brandup, J.; Immergut, E. H. Polymer Handbook; Wiley: New York,1999.

(32) Muller, A.J.; Balsamo, V.; Arnal, M.L.; Jakob, T.; Schmalz, H.; Abetz, V. Homogeneous Nucleation and Fractionated Crystallization in Block Copolymers. Macromolecules 2002, 35, 3048-3058.

(33) Finch, C. A. Polymer Handbook; Brandrup, J., Immergut, E. H., Eds.; Wiley-Interscience: Chichester, 1989.

(34) Fetters, L. J.; Lohse, D. J.; Richter, D.; Witten, T. A.; Zirkel, A. Connection between Polymer Molecular Weight, Density, Chain Dimensions, and Melt Viscoelastic Properties. Macromolecules 1994, 27, 4639. 
(35) Lheritier, J.; Chauvet, A.; Masse, J.; Study of SR 33557/PEG 6000 interactions. Thermochim. Acta 1994, 241, 157-169.

(36) Hamley, I.W.; Castelletto, V. Small-angle scattering of block copolymers. Prog. Polym. Sci. 2004, 29, 909-948.

(37) Kim, S. H.; Misner, M. J.; Xu, T.; Kimura, M.; Russell, T.P. Highly oriented and ordered arrays from block copolymers via solvent evaporation. Adv. Mater. 2004, 16, 226-231.

(38) Chieffi, G.; Di Girolamo, R.; Aronne, A.; Pernice, P.; Fanelli, E.; Lazzari, M.; De Rosa, C.; Auriemma, F. Rapid-flux-solvent-atmosphere method for tailoring the morphology of titania substrates over a large area via direct self-assembly of block copolymers. $R S C A d v . \mathbf{2 0 1 4}, 4$, $16721-16725$.

(39) Luo, C.; Zhang, Y.; Wang, Y. Palladium nanoparticles in poly(ethylene glycol): an efficient and recyclable catalyst for the Heck reaction. J. Mol. Catal. A: Chem. 2005, 229, 7-12.

(40) Harraz, F. A.; El-Hout, S. E.; Killa, H. M.; Ibrahim, I.A. Palladium nanoparticles stabilized by polyethylene glycol: Efficient, recyclable catalyst for hydrogenation of styrene and nitrobenzene. J. Catal. 2012, 286, 184-192.

(41) Farrauto, R. J.; Lampert, J. K.; Hobson, M. C.; Waterman E. M. Thermal decomposition and reformation of PdO catalysts; support effects. Appl. Catal., B 1995, 6, 263-270.

(42) Datye, K.; Bravo, J.; Nelson, T. R.; Atanasova, P.; Lyubovsky, M.; Pfefferle, L. Catalyst microstructure and methane oxidation reactivity during the $\mathrm{Pd} \leftrightarrow \mathrm{PdO}$ transformation on alumina supports. Appl. Catal., A 2000, 198, 179-196. 
(43) Swanson, H. E.; Tatge, E. Standard X-Ray Diffraction Powder Patterns. Natl. Bur. Stand. Circ. 539 1953, 1, 21.

(44) Welton-Holzer, J.; McCarthy, G. North Dakota State University, Fargo, North Dakota, USA. ICDD Grant-in-Aid 1989.

Table of Contents

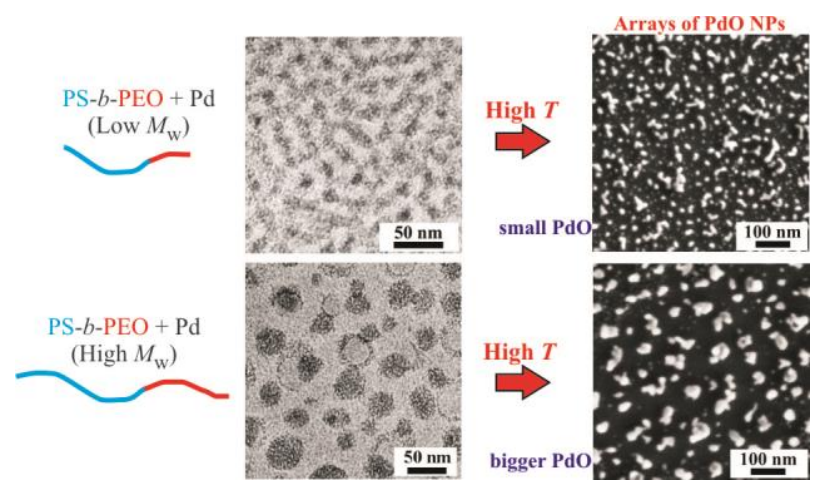

